Jia-Ying Lee*

Department of English

Tamkang University, Taiwan

jylee@mail.tku.edu.tw

\title{
TEACHING TEST-TAKING STRATEGIES TO EFL STUDENT READERS WITH DIFFERENT LANGUAGE PROFICIENCIES: AN EMPIRICAL REASSESSMENT
}

\section{Abstract}

This study investigated the effect of teaching test-taking strategies to EFL student readers with different levels of reading proficiency (i.e. high and low). Two groups of undergraduate non-English majors joined an eight-week experiment. One served as the treatment group (TG) which learned test-taking strategies to tackle English reading test tasks, while the control group (CG) received no strategy instruction. The pretest and posttest reading performances of all the participants from the TG and CG were quantitatively compared. Additionally, the TG's use of test-taking strategies was investigated by means of entry and exit surveys. The results show that the students at both proficiency levels of the TG made significantly greater gains in the reading posttest compared with the pretest, and they also significantly outperformed their counterparts from the CG on the posttest. The participants from both levels of the TG also used significantly more test-taking strategies than before, but they used some strategies more frequently than others. Taken together, the results support the pedagogical effects of the instruction in test-taking strategies in EFL reading classes.

\section{Key words}

test-taking strategies, reading strategies, strategy instruction.

\footnotetext{
* Corresponding address: Jia-Ying Lee, Department of English, Tamkang University, No. 151, Yingzhuan Rd., Tamsui Dist., New Taipei City 25137, Taiwan.
} 


\section{INTRODUCTION}

Reading comprehension is a complex process. When learners read in their first language or a foreign language, they begin a series of conscious cognitive processes, such as analyzing sentence meaning, breaking down the grammatical structure of sentences, translating the foreign language into their native language in order to understand it, and then integrating the information contained in each paragraph in order to critically analyze the text. Because reading is such a highly complex cognitive behavior, many scholars have explored the process whereby students gain the ability to understand what they are reading. For example, the patterns of early research on reading comprehension include "top-down" (i.e. from reader to text) (Goodman, 1967) and "bottom-top" (i.e. from text to reader) (Smith, 1985). A. H. Urquhart and Weir (2014) and S. Urquhart and Weir (1998) have proposed the research concepts of "reading level" and "reading type" 1 , and scholars such as Bernhardt (2005), Grabe (2009), and Macaro and Erler (2008) have set out ways of combining these reading models to facilitate development of reading in learners. Following this line of discussion, a growing number of researchers have started to study the acquisition of reading comprehension by examining the interaction between readers and written texts (e.g. Grabe, 2004; A. H. Urquhart \& Weir, 2014). The appearance of such studies demonstrates that reading comprehension is a difficult but important research topic and that the teaching of reading should focus not only on the construction of vocabulary but also on finding ways to connect the meaning of a text with its readers (Tierney, 2005).

To improve students' reading ability or reading achievement beyond their existing cognitive capacity for reading (Pressley, 2006), a substantial number of research studies and discussions about "reading strategies" have been made over the last few decades. Reading strategies can be seen as a series of conscious mental activities that readers use to overcome their reading challenges. In addition to comprehensive planning strategies, monitoring strategies, and evaluation strategies $^{2}$ (Phakiti, 2003), and reading studies (e.g. Akkakoson, 2013; BoulwareGooden, Carreker, Thornhill, \& Joshi, 2007; Karimi, 2015; Salatacı \& Akyel, 2002; Schwartz, Mendoza, \& Meyer, 2017) are increasingly focusing on cognitive and metacognitive strategies, and authors agree that the frequency of using these

\footnotetext{
1 "Reading level" refers either to the process of reading or the level of integration skills into the act of reading. In the process of reading, the level is determined by whether the text is more oriented to the ability to understand some parts (such as a lower-level understanding of prepositions) or to the ability to comprehensively understand the whole (such as a higher-level comprehensive understanding that goes beyond prepositions). "Reading type" can refer to one of the following two terms: "speed reading" and "careful reading".

2 "Planning strategies" generally refer to the reader's behaviors in previewing or summarizing, and also to decisions about the way to complete the reading tasks and the steps that must be taken. "Monitoring strategies" refer to the conscious behaviors of a reader who monitors his or her task performance to ensure that the task is fully completed. "Evaluation strategies" refer to the strategies that readers use to identify or evaluate the extent to which they can perform a task.
} 
strategies is significantly correlated with and significantly benefits learners' reading achievement. Moreover, studies on the application of reading strategies have been oriented to testing the feasibility of teaching reading strategies (Karimi, 2015), which has led to an increasing number of experts engaging in research on "strategy instruction" in reading in a second or foreign language (Akkakoson, 2013; Green, 2016; Karimi, 2015; Macaro \& Erler, 2008; Spörer, Brunstein, \& Kieschke, 2009). It is expected that, if they are summarized and taught, effective reading strategy categories can provide a reader who has relatively low learning skills with effective strategy training in reading.

Indeed, research on reading strategies has produced substantial positive empirical evidence to support the training of educators in teaching reading strategies. For example, Spörer et al. (2009) have found that reading comprehension and strategy application among students who received training in reading strategies were significantly better than those of untrained students. A study by Salatacı and Akyel (2002), examining the effects of multiple reading strategies on EFL (English as a foreign language) Turkish college students, indicated that reading strategies significantly improves those students' reading performance. Similarly, in a study by Zhang (2008), a group of 99 EFL college students whose native language was Chinese received eight weeks of training in reading strategies. After this training, the students' reading strategy behaviors significantly and positively changed, and their reading comprehension ability also improved. Similar findings were also found in an experiment by Akkakoson (2013), who used Thai students as subjects to examine the relationship between strategic reading training and reading achievement. In the pretest and posttest comparison, the reading performance and strategy application ability of the experimental group were better than those of the control group. In addition, the effect on higher level readers of applying the strategies with higher level readers was greater than that on readers with weaker reading skills. A previous study by Boulware-Gooden et al. (2007) showed that multiple metacognitive reading strategies were effective in improving vocabulary achievement and reading comprehension. In this study, 119 students in the experimental group had a significant increase of $40 \%$ in vocabulary acquisition, and their reading comprehension was also better than that of the students in the control group, who did not receive the metacognitive strategy training, thereby endorsing the use of multiple strategies. A similar study was conducted later by Maier and Richter (2014), who also examined the effects of different metacognitive strategies on 85 foreign language learners, and verified that metacognitive strategies can effectively improve learners' reading performance. Many scholars in recent years have also consistently verified the effectiveness of instruction in reading strategies. For instance, Karimi (2015) used 76 EFL students as subjects and taught them reading strategies to improve their reading comprehension of multiple literary texts. This study demonstrated significant achievements and extended the effect of teaching reading strategies on the reading comprehension of one type of text to consider the effect of multiple 
sources. Other recent publications also confirming the benefits of teaching reading strategies include the studies by Schwartz et al. (2017) and Ying-Chun, Chern, and Reynolds (2018), which verified the effectiveness of teaching reading strategies as a way of enhancing EFL students' reading comprehension, and further confirmed the feasibility of teaching reading strategies.

In addition to the research on effectively improving reading comprehension by using reading strategies, the use of strategies in reading tests has also gradually gained increasing attention and positive comments from reading experts and scholars (Cohen \& Upton, 2007; Lee, 2018). First, in the field of language testing, studies have pointed out a significant positive correlation between test-taking strategies and language test performance (Cohen \& Upton, 2007); such strategies can help examinees understand test items or tasks more effectively (Huang, 2016; Phakiti, 2003; Zhang, Goh, \& Kunnan, 2014). Cohen and Upton (2007) have tested the strategies that help examinees familiarize themselves with the TOEFL iBT test. For example, in the Basic Comprehension-vocabulary section, the most common test-taking strategy is to obtain the correct answer by jumping directly to the words before and after the blanks, whereas in the Basic Inference section, a common strategy is to look for relevant clues from the article and raise the accuracy rate by first removing incompatible options. Zhang et al. (2014) further investigated the relationship between cognitive and metacognitive strategies used by EFL examinees and found that the test-taking strategies used by research participants had a positive effect on their reading test scores. This research finding also corresponds to the findings of a previous study by Phakiti (2003), who examined the correlation between test-taking strategies and reading test scores. These results also confirmed the significant positive correlation between testtaking strategies and reading test scores. However, although numerous studies currently support the teaching of reading strategies (e.g. Green, 2016; Karimi, 2015; Macaro \& Erler, 2008; Schwartz et al., 2017; Spörer et al., 2009), research investigating the effectiveness of teaching test-taking strategies in the field of foreign language reading is still scarce (Chalmers \& Walkinshaw, 2014; Cohen, 2006; Plonsky, 2011). In particular, little has been discovered about the effects of teaching test-taking strategies to students with different levels of reading proficiency.

\section{THE PRESENT STUDY}

\subsection{Aim and research questions}

To shed light on the pedagogical effects of teaching test strategies to EFL students with different reading proficiencies, an experiment was conducted with two groups of EFL student readers. One group learned test-taking strategies (that is, the 
treatment group: TG) and the other received no such instruction (the control group: CG). This study was designed to answer the two research questions shown below:

1. After the strategy instruction, do the TG and CG participants with different reading proficiency levels perform differently from each other in the posttest reading?

2. After the strategy instruction, are there any significant differences in the use of test-taking strategies by the TG participants with different reading proficiency levels?

\subsection{Participants}

This study, based at a university in Taiwan, first recruited 130 second-year nonEnglish-major undergraduate students. After consenting to the experiment, half of the participants were assigned to the treatment group (TG) to study test-taking strategies with the researcher. The other half served as the contrast group (CG), receiving no strategy instruction but studying reading skills, also with the researcher, through reading printed articles. Most of the participants in both groups were 18-19 years old. Before enrolling, they had learned English for at least 10 years. The level of English proficiency in the groups was around B1 according to the Common European Framework of Reference for Languages, with only a few students at $\mathrm{A} 2$ or $\mathrm{B} 2$ levels.

It should be noted that all of the 130 participants completed the experiment. However, for the purpose of comparing differences between participants of different levels (i.e. high versus low, for this study), only the data of the top $1 / 3$ and the bottom $1 / 3$ of both groups were later collected for analysis, the medium $1 / 3$ being ignored. This course was chosen in response to the results of the reading achievement pretest, which is described below.

\subsection{Procedure}

Both groups met for 50 minutes per week for 8 weeks. During this period, the TG learned about the 24 test-taking strategies (see Appendix 1) that Lee (2018) had found effective in empowering student readers when they tackled English reading tests. Lee (2018) grouped the 24 strategies into four categories according to their features and function. Category 1 contained word-based/lexico-grammatical testtaking strategies (six items); Category 2 consisted of sentence-based test-taking strategies (five items); Category 3 was composed of reading comprehension testtaking strategies (eight items); and Category 4 comprised technical test-taking strategies (five items). Every two weeks, the TG studied one category, every strategy of which was first explained to them in detail and then demonstrated 
using specific test samples. For example, when teaching Strategy 10 (i.e. jumping immediately to the part which contained the missing word and focusing on the neighboring words), the teacher-researcher would first provide the TG with the following description:

\begin{abstract}
"This strategy is effective and efficient for tackling sentence/text completion tasks. In practice, you may skip the parts that are not being asked about and see if a decision can be reached after interpreting the information on either side of the missing word. This strategy can also help save time. If a decision cannot be reached, then read more parts of the sentence(s) to look for more clues to a possible answer."
\end{abstract}

After the explanation, the strategy would be demonstrated with some sample tasks. An example is given below:

"For example, in this long text below, if you skip to the information around the missing word, you will notice that the parts Sydney's largest tourist and drawing three million visitors before and after the missing word. These give a clear clue to the answer, namely, option (D) attractions."

( ) Q1. The existing market sells more than 25 million pounds of seafood each year to consumers and distributors (making it the world's third-largest fish market), but it's also one of Sydney's largest tourist 1. drawing three million visitors each year.
(A) distributions
(B) deliveries
(C) emendations
(D) attractions

In contrast, the CG studied reading materials with the researcher to develop reading skills (e.g. vocabulary, grammar, collocations, appreciation of articles), concentrating every two weeks on one article from the textbook Active 4: Skills for Reading (Anderson, 2014), which their university often prescribed for non-English majors. For example, when studying a new article, the researcher would first discuss with the class the definitions of key words and meanings of the main vocabulary items that the author had used. The collocations and grammar associated with the vocabulary were also presented when necessary. For instance, when learning about the word compose, the class was taught that it was used either as a transitive verb or in a passive formula: be composed of. Likewise, when they came across complex sentences or grammatical structures, the researcher would analyze them to make it easier for the students to understand them. Here is an example from the textbook: "The idea to study the Tarahumaras came to Copeland in 1984, when he discovered that very little research had been done on their language" (Anderson, 2014: 182). The researcher would explain to the class the function of the when-clause here and why the past perfect tense passive verb (i.e. had been done) was used. Finally, the students were asked to reflect upon the main 
idea of the article, discuss how it could be more generally applied, or relate it to their personal experience.

\subsection{Instruments}

Reading Tests. To assess the participants' reading performance, this study adopted the reading section of TOEIC (the Test of English for International Communication) (cf. www.ets.org/toeic), an English-language proficiency test that the Educational Testing Service (ETS: www.ets.org) has created for non-native English speakers. The TOEIC reading section measures English reading skills in an international context. It allows test takers a total of 75 minutes to complete 100 multiple-choice questions on Sentence Completion (40 items), Text Completion (12 items), and Reading Comprehension (48 items).

However, the present study was constrained by time and resources, so the researcher instead randomly selected two sets of TOEIC reading tests officially published by the ETS for public use and modified them into two shorter versions, with equal numbers of items, all of equal difficulty. Next, she discussed this with three other experienced college teachers of English reading. Both revisions, reallocated and with only 40 minutes to complete them, comprised 20 questions on Sentence Completion, 6 on Text Completion, and 24 on Reading Comprehension. The revised versions were then randomly assigned to a pretest or a posttest.

Strategy survey. The test-taking strategy survey (Appendix 2) used in this study adopted work by Lee (2018), which was used to assess the respondents' use of the 24 test-taking strategies that had been taught in the present study. The questions used a five-point Likert scale, with larger numbers indicating that a respondent used a particular item more frequently and smaller numbers indicating less frequent use. Lee (2018) had tested the survey in a pilot study of 120 students and found it to be highly reliable (Cronbach alpha $=.85$ ).

\subsection{Data analysis}

The data obtained from the TOEIC reading tests and strategy surveys were statistically analyzed. Descriptive statistics first show the TOEIC pretest results for both TG and CG, with the top $1 / 3$ scorers labeled high level and the bottom $1 / 3$ low level. Second, independent $t$ tests were used to examine the TOEIC pretest scores to see whether the TG and CG had similar levels of reading proficiencies on entry. Third, paired sample $t$ tests examined whether both groups, whatever their level, had improved their reading performance, whatever their level, after the treatment. Both the descriptive statistics and paired sample $t$ tests then examined whether the TG had changed their strategy use between the entry and exit strategy 
surveys. Finally, independent $t$ tests were used a second time to examine whether the TG and CG differed on the TOEIC posttests. The effect sizes of all the $t$ test results are listed below using Cohen's $d$, with .40 indicating a small effect size, .70 medium, and 1.00 large (cf. Plonsky \& Oswald, 2014).

\section{RESULTS}

\subsection{Entry reading proficiency}

Table 1 presents the descriptive statistics of the reading performance pretest results for both groups. Each group's top 1/3 scorers, namely, those who got 41 points or above, were labeled high level (TG: 23 students; CG: 26), and the bottom 1/3 low level students were those who scored 38 points or below (TG: 24 students; CG: 23). Independent $t$ tests further showed non-statistical differences between the groups in terms of both levels (high: $t=.673, p=.504$; low: $t=-1.799$; $p=.077$ ) (see Table 2). These results mean that on entry the groups had similar levels of reading proficiency.

\begin{tabular}{|l|l|l|l|l|l|l|}
\hline GrouP & LEVELS & N & MIN. & MAX. & MEAN & SD \\
\hline TG & High & 23 & 41 & 47 & 42.78 & 2.33 \\
\hline & Low & 24 & 32 & 38 & 35.88 & 2.07 \\
\hline CG & High & 26 & 41 & 47 & 42.46 & 1.53 \\
\hline & Low & 23 & 34 & 38 & 36.78 & 1.28 \\
\hline
\end{tabular}

Table 1. Descriptive statistics for the reading pretest of both groups

\begin{tabular}{|c|c|c|c|c|c|c|}
\hline LEVEL & $\boldsymbol{T}$ & $\boldsymbol{D F}$ & $\boldsymbol{P}$ & MEAN DIFFERENCE & SE & $\boldsymbol{D}$ \\
\hline High & .673 & 47 & .504 & .32 & .48 & .21 \\
Low & -1.799 & 38.541 & .077 & -.90 & .50 & .70 \\
\hline
\end{tabular}

Table 2. The independent $t$ test results for the reading pretest between the groups

\subsection{Changes in reading performance after the experiment}

While Table 3 presents the descriptive statistics of the reading performance by both groups in the posttest, Table 4 compares the pre- and posttest results of both groups' reading performance. As Table 4 summarizes, after the treatment, the statistics for both levels show that the TG significantly improved their reading performance (high: $t(22)=-4.602, p=.000$; low: $t(23)=-11.734, p=.000$ ), to a medium to large effect size ( $d=.77$ and 2.54 , respectively). Additionally, students 
in the low level TG made a greater gain (the mean difference: -5.25 ) than the high level TG students did (-1.78). In contrast, however, the results of the students in the high-level CG were found to have deteriorated $(t(25)=5.250, p=.000, d=$ 1.10) whereas the low-level CG students made statistically significant improvements $(t(22)=-3.404, p=.003)$ with a large effect size $(d=1.29)$. These mixed findings require clarification by further analysis.

\begin{tabular}{|l|l|l|l|l|l|l|}
\hline GROUP & LEVELS & N. & MIN. & MAX. & MEAN & SD \\
\hline \multirow{2}{*}{ TG } & High & 23 & 40 & 48 & 44.57 & 2.33 \\
\cline { 2 - 7 } & Low & 24 & 35 & 46 & 41.13 & 2.80 \\
\hline CG & High & 26 & 38 & 47 & 40.77 & 1.66 \\
\cline { 2 - 7 } & Low & 23 & 34 & 43 & 38.43 & 2.35 \\
\hline
\end{tabular}

Table 3. Descriptive statistics for the reading posttest of both groups

\begin{tabular}{|l|l|l|l|l|l|l|l|l|}
\hline \multirow{2}{*}{ GROUP } & LEVELS & $\mathbf{N}$ & $\begin{array}{l}\text { MEAN DIFFERENCE } \\
\text { (PRETEST - } \\
\text { POSTTEST }\end{array}$ & SE & DF & T & $\boldsymbol{P}$ & $\boldsymbol{D}$ \\
\hline TG & High & 23 & -1.78 & 1.86 & 22 & -4.602 & .000 & .77 \\
\cline { 2 - 9 } & Low & 24 & -5.25 & 2.19 & 23 & - & .000 & 2.54 \\
\hline CG & High & 26 & 1.69 & 1.64 & 25 & 5.250 & .000 & 1.10 \\
\cline { 2 - 9 } & Low & 23 & -1.65 & 2.33 & 22 & -3.404 & .003 & 1.29 \\
\hline
\end{tabular}

Table 4. Paired sample $t$ test on the pre- and posttest TOEIC scores of the TG and CG

Table 5 further shows statistically significant differences between the groups in terms of both levels (high: $t=6.491, p=.000$; low: $t=3.557, p=.001$ ), with great effect ( $d=2.29$ and 1.15 , respectively). This suggests that, regardless of their level, the TG significantly outperformed the CG, confirming that the results may be ascribed to the effects of treatment and validating the instructional effects of the test-taking strategy instruction.

\begin{tabular}{|c|c|c|c|c|c|c|}
\hline LEVEL & $\boldsymbol{T}$ & $\boldsymbol{D F}$ & $\boldsymbol{P}$ & MEAN DIFFERENCE & SE & $\boldsymbol{D}$ \\
\hline High & 6.491 & 39.1591 & .000 & 3.80 & .58 & 2.29 \\
Low & 3.557 & 45 & .001 & 2.69 & .76 & 1.15 \\
\hline
\end{tabular}

Table 5. The independent $t$ test results for the reading posttest between the groups 


\subsection{Changes in test-taking strategy use after the experiment}

Table 6 presents the paired sample $t$ test results of the TG students' entry and exit surveys, lending further support to the effects of the experimental treatment noted above. First, statistically significant differences were found in the uses of an overall strategy and those of Categories 1, 2, and 3 for both the high-level (overall strategy: $t(22)=-4.252, p=.000$; Category $1: t(22)=-4.191, p=.000$; Category 2 : $t(22)=-3.847, p=.001$; Category 3: $t(22)=-2.240, p=.036)$ and the low-level groups (overall: $t(23)=-3.167, p=.004$; Category $1: t(23)=-2.717, p=.012$; Category 2: $t(23)=-3.493, p=.002$; Category 3: $t(23)=-2.074, p=.049)$, with effect sizes ranging from small to great. These suggest that the treatment had a statistically significant effect on the TG students' learning of the test-taking strategies, except for those of Category 4, since no statistical difference was found in this category for either the high-level $(t(22)=-1.121, p=.274, d=.22)$ or lowlevel groups: $t(23)=-1.260, p=.220, d=.26$.

\begin{tabular}{|c|c|c|c|c|c|c|c|c|c|}
\hline LEVELS & STRATEGY & SURVEY & $\mathbf{N}$ & MEAN & SD & $D F$ & $T$ & $P$ & $D$ \\
\hline \multirow{5}{*}{ High } & $\begin{array}{c}\text { Category 1: } \\
\text { Word-based /lexico- } \\
\text { grammatical }\end{array}$ & $\begin{array}{l}\text { Entry } \\
\text { Exit }\end{array}$ & $\begin{array}{l}23 \\
23\end{array}$ & $\begin{array}{l}20.30 \\
24.35\end{array}$ & $\begin{array}{l}3.75 \\
4.23\end{array}$ & 22 & -4.191 & .000 & 1.08 \\
\hline & $\begin{array}{c}\text { Category 2: } \\
\text { Sentence-based }\end{array}$ & $\begin{array}{l}\text { Entry } \\
\text { Exit }\end{array}$ & $\begin{array}{l}23 \\
23\end{array}$ & $\begin{array}{l}16.35 \\
19.70\end{array}$ & $\begin{array}{l}3.51 \\
2.42\end{array}$ & 22 & -3.847 & .001 & .95 \\
\hline & $\begin{array}{l}\text { Category 3: } \\
\text { Reading comprehension }\end{array}$ & $\begin{array}{l}\text { Entry } \\
\text { Exit }\end{array}$ & $\begin{array}{l}23 \\
23\end{array}$ & $\begin{array}{l}26.83 \\
30.04\end{array}$ & $\begin{array}{l}4.86 \\
3.96\end{array}$ & 22 & -2.240 & .036 & .66 \\
\hline & $\begin{array}{c}\text { Category 4: } \\
\text { Technical approaches }\end{array}$ & $\begin{array}{c}\text { Entry } \\
\text { Exit }\end{array}$ & $\begin{array}{l}23 \\
23\end{array}$ & $\begin{array}{l}18.39 \\
19.09\end{array}$ & $\begin{array}{l}3.23 \\
2.70\end{array}$ & 22 & -1.121 & .274 & .22 \\
\hline & Overall & $\begin{array}{l}\text { Entry } \\
\text { Exit }\end{array}$ & $\begin{array}{l}23 \\
23\end{array}$ & $\begin{array}{l}81.87 \\
93.17\end{array}$ & $\begin{array}{c}9.10 \\
10.99\end{array}$ & 22 & -4.252 & .000 & 1.24 \\
\hline \multirow{5}{*}{ Low } & $\begin{array}{c}\text { Category 1: } \\
\text { Word-based /lexico- } \\
\text { grammatical }\end{array}$ & $\begin{array}{l}\text { Entry } \\
\text { Exit }\end{array}$ & $\begin{array}{l}24 \\
24\end{array}$ & $\begin{array}{l}21.98 \\
23.83\end{array}$ & $\begin{array}{l}4.38 \\
2.55\end{array}$ & 23 & -2.717 & .012 & .42 \\
\hline & $\begin{array}{c}\text { Category 2: } \\
\text { Sentence-based }\end{array}$ & $\begin{array}{c}\text { Entry } \\
\text { Exit }\end{array}$ & $\begin{array}{l}24 \\
24\end{array}$ & $\begin{array}{l}16.33 \\
20.33\end{array}$ & $\begin{array}{l}4.76 \\
1.90\end{array}$ & 23 & -3.493 & .002 & .84 \\
\hline & $\begin{array}{c}\text { Category 3: } \\
\text { Reading comprehension }\end{array}$ & $\begin{array}{c}\text { Entry } \\
\text { Exit }\end{array}$ & $\begin{array}{l}24 \\
24\end{array}$ & $\begin{array}{l}27.71 \\
30.08\end{array}$ & $\begin{array}{l}4.11 \\
3.59\end{array}$ & 23 & -2.074 & .049 & .58 \\
\hline & $\begin{array}{c}\text { Category 4: } \\
\text { Technical approaches }\end{array}$ & $\begin{array}{c}\text { Entry } \\
\text { Exit }\end{array}$ & $\begin{array}{l}24 \\
24\end{array}$ & $\begin{array}{l}18.08 \\
18.63\end{array}$ & $\begin{array}{l}2.10 \\
2.48\end{array}$ & 23 & -1.260 & .220 & .26 \\
\hline & Overall & $\begin{array}{l}\text { Entry } \\
\text { Exit }\end{array}$ & $\begin{array}{l}24 \\
24\end{array}$ & $\begin{array}{l}83.50 \\
92.88\end{array}$ & $\begin{array}{c}11.55 \\
8.39\end{array}$ & 23 & -3.167 & .004 & .81 \\
\hline
\end{tabular}

Table 6. Paired sample $t$ test results for the entry and exit survey scores of the TG students 


\section{DISCUSSION}

In this study, in response to the call for more empirical investigations into the effects of teaching test-taking strategies in the context of foreign language reading (Chalmers \& Walkinshaw, 2014; Cohen, 2006; Plonsky, 2011), an experiment with two groups of EFL undergraduate students was carried out. The TG was taught test-taking strategies whereas the CG was given no such instruction. It was found that, in the reading test, both proficiency levels of the TG made significantly greater gains on their previous scores, and in the posttest they outperformed their counterparts in the CG. Both levels of the TG also used test-taking strategies significantly more often than before, although Category 1, 2, and 3 strategies were employed more than were those in Category 4 . Taken together, the findings merit discussion.

First, the findings of this study substantiate the claims by previous scholars about the positive effects of reading-related strategies on reading comprehension in general. To begin with, the finding that students of both levels of proficiency in the TG improved their reading test performance upholds the argument by Chang (2010), Grabe (2009), and Schwartz et al. (2017) that the use of reading-related strategies can lead to improved reading performance. This endorsement further supports the general recommendation that reading-related strategies, such as reading strategies or reading test-taking strategies, should be taught to student readers to enhance their comprehension of written texts (cf. Block, 1992; Chen, 2017; Grabe, 2009). It also echoes the specific reports by Akkakoson (2013), Karimi (2015) and Macaro and Erler (2008), in which effective strategy instruction was found to advance reading performance.

In addition to validating the claims in the literature about reading comprehension strategies and reading performance in general, the results of the present study also clearly support several prior studies in the specific domain of language assessment, making important contributions to the field. Specifically, the result that both the use of strategy by the TG and their reading test scores significantly increased confirms the positive association between the use of testtaking strategies and language test performance as reported by Huang (2016), Phakiti (2003), and Zhang et al. (2014). This specific finding further strengthens Gebril's (2018) contention that test-taking strategies can effectively help language learners gain better scores in tests. More importantly, both levels of the TG statistically significantly improved their reading performance and outperformed their counterparts in the CG. This validates the instructional need and relevance of teaching test-taking strategies to student readers, and in turn justifies the earlier call for more empirical investigations in this field (Chalmers \& Walkinshaw, 2014; Cohen, 2006; Plonsky, 2011) to which the present study is a response.

The reasons why some test-taking strategies were used more or less often than others after the instruction are worth discussing. First of all, after training, both levels of the TG employed strategies in Categories 1, 2, and 3 significantly 
more often, but did not employ those in Category 4. While this seems to imply that Categories 1, 2, and 3 strategies were instructionally more feasible than those in Category 4, it seems more likely that technical approaches (i.e. those of Category 4) are perhaps simply not as effective as the cognitive strategies in Categories 1,2 , and 3 in tackling reading comprehension tasks, so the former was generally less often used/felt necessary. A stronger version of the above argument is that the more frequent use of the cognitive strategies had already more effectively developed the participants' understanding and thus diminished their need to base their answers on technical approaches, which are mostly used by people who struggle with reading comprehension. To be precise, Strategy 20 refers to eliminating answer options so as to leave one that is more feasible; Strategy 21 refers to reminding test-takers struggling with answer options to focus on the phrases which may contain answers; Strategy 22 asks them to skip difficult questions in order to save time; Strategy 23 basically provides a sensible principle for guesswork; and Strategy 24 reminds test-takers to notice whether the amount of time left requires them to adjust their pace. Even so, this does not mean that Category 4 should be removed from the test-taking strategies because, as the results have shown, the TG students, regardless of their proficiency, still used them, and indeed used more of them than before. This clearly shows that Category 4 strategies could still be of advantage to test-takers at times when they find reading comprehension difficult.

Most importantly, the greatest gain was found among the low-level TG. This demonstrates the theoretical proposition by Canale and Swain (1980): that the effective deployment of strategies can compensate for insufficient language knowledge by means of enhancing students' ability to read and thus improving reading comprehension. This is a salient point, given that, although the CG significantly improved their scores by being taught general reading skills (e.g. grammar, vocabulary, and article reading), their reading test scores were still significantly below those of the TG, who were trained to use test-taking strategies alone, rather than skills or knowledge related to English reading.

\section{LIMITATIONS AND SUGGESTIONS FOR FUTURE STUDIES}

While the discussion tends to acknowledge the usefulness of teaching test-taking strategies, it should also be admitted that the present study has some limitations. First, the sample size of this study risks being unrepresentative of the whole population of EFL student readers. Future scholars may consider a larger sample or the recruitment of other participants than college students, so as to further verify whether test-taking strategies can be safely introduced to a wider range of EFL reading classes. Likewise, this study examined only the 24 test-taking strategies that Lee (2018) had identified. Whether similar effects would be found with other test-taking strategies is worth investigating. In the same way, this study 
investigated the participants' levels of reading proficiency and reading comprehension performance with tests of the multiple-choice format only. It would be useful to investigate whether or not students would also do better with test-taking strategies of different types if their tests had other important formats (e.g. open-ended questions, summary tasks, or gap-filling tasks). In addition, the present study determined the pedagogical effects of the test-taking strategy instruction by means of reading test strategies and performances and failed to take into consideration another equally important aspect of successful learning, namely, participants' learning attitudes (e.g. learning motivation or self-efficacy). Future researchers may wish to look into this to form a more thorough presentation of the comprehensive effects of training student readers in test-taking strategies. Finally, it must not be forgotten that the test-taking strategy instruction was delivered in a teacher-centered manner, with the teacher didactically explaining and demonstrating how those strategies should be perceived and practiced. Whether or not student readers would benefit more or less from different approaches to learning test-taking strategies (e.g. the communicative approach, the metacognitive approach, or content and language integrated learning) awaits investigation.

\section{CONCLUSION}

This paper reports an empirical assessment of the effects of teaching test-taking strategies to EFL undergraduate student readers. The study results are particularly meaningful in confirming that test-taking strategies are pedagogically suitable and effective for students of widely different levels of reading proficiency. Additionally, it verified that some test-taking strategies may be easier for test takers to adopt or may be perceived as more effective in coping with reading tasks. However, this does not mean that the less frequently used test-taking strategies are useless, and thus do not deserve to be taught. As the results of this study have shown, they were still employed, although less frequently than the others. Instead, it may be more logical to interpret this as a sign that different strategies may complement or compensate for each other in tackling reading test tasks, and should therefore be taught together.

[Paper submitted 14 Feb 2019]

[Revised version received 2 May 2019]

[Revised version accepted for publication 3 Jun 2019]

\section{Acknowledgement}

This article was written with funding support from Taiwan's Ministry of Science and Technology (MOST 107-2410-H-032-057). 


\section{References}

Akkakoson, S. (2013). The relationship between strategic reading instruction, student learning of L2-based reading strategies and L2 reading achievement. Journal of Research in Reading, 36(4), 422-450. https://doi.org/10.1111/jrir.12004

Anderson, N. J. (2014). Active 4: Skills for reading (3rd ed.). Boston, MA: Heinle ELT.

Bernhardt, E. B. (2005). Progress and procrastination in second language reading. Annual Review of Applied Linguistics, 25, 133-150. https://doi.org/10.1017/S0267190505000073

Block, E. (1992). See how they read: Comprehension monitoring of L1 and L2 readers. TESOL Quarterly, 26(2), 319-341. https://www.jstor.org/stable/3587008

Boulware-Gooden, R., Carreker, S., Thornhill, A., \& Joshi, R. (2007). Instruction of metacognitive strategies enhances reading comprehension and vocabulary achievement of third-grade students. The Reading Teacher, 61(1), 70-77. https://doi.org/10.1598/RT.61.1.7

Canale, M., \& Swain, M. (1980). Theoretical bases of communicative approaches to second language teaching and testing. Applied Linguistics, 1(1), 1-47. https://doi.org/10.1093/applin/I.1.1

Chalmers, J., \& Walkinshaw, I. (2014). Reading strategies in IELTS tests: Prevalence and impact on outcomes. English Australia Journal, 30(1), 24-39.

Chang, C. (2010). See how they read: An investigation into the cognitive and metacognitive strategies of nonnative readers of Chinese. In M. E. Everson, \& H. H. Shen (Eds.), Chinese language teachers association monograph series: Research among learners of Chinese as a foreign language (Vol. 4, pp. 93-116). University of Hawai'i: National Foreign Language Resource Center.

Chen, K. T. C. (2017). An exploratory study of NNES graduate students' reading comprehension of English journal articles. Reading in a Foreign Language, 29(1), 20-35.

Cohen, A. D. (2006). The coming of age of research on test-taking strategies. Language Assessment Quarterly, 3(4), 307-331. https://doi.org/10.1080/15434300701333129

Cohen, A. D., \& Upton, T. A. (2007). "I want to go back to the text": Response strategies on the reading subtest of the new TOEFL. Language Testing, 24(2), 209-250. https://doi.org/10.1177/0265532207076364

Gebril, A. (2018). Test preparation in the accountability era: Toward a learning-oriented approach. TESOL Journal, 9(1), 4-16. https://doi.org/10.1002/tesj.302

Goodman, K. S. (1967). Reading: A psycholinguistic guessing game. Literacy Research and Instruction, 6(4), 126-135.

Grabe, W. (2004). Research on teaching reading. Annual Review of Applied Linguistics, 24, 44-69. https://doi.org/10.1017/S0267190504000030

Grabe, W. (2009). Reading in a second language: Moving from theory to practice. New York, NY: Cambridge University Press.

Green, S. (2016). Two for one: Using QAR to increase reading comprehension and improve test scores. The Reading Teacher, 70(1), 103-109. https://doi.org/10.1002/trtr.1466

Huang, H. T. D. (2016). Exploring strategy use in L2 speaking assessment. System, 63, 1327. https://doi.org/10.1016/j.system.2016.08.009

Karimi, M. N. (2015). EFL learners' multiple documents literacy: Effects of a strategy-directed intervention program. The Modern Language Journal, 99(1), 40-56. https://doi.org/10.1111/modl.12192

Lee, J-Y. (2018). The use of test-taking strategies and students' performances in answering TOEIC reading comprehension questions. Taiwan Journal of TESOL, 15(2), 33-64. 
Macaro, E., \& Erler, L. (2008). Raising the achievement of young-beginner readers of French through strategy instruction. Applied Linguistics, 29(1), 90-119. https://doi.org/10.1093/applin/amm023

Maier, J., \& Richter, T. (2014). Fostering multiple text comprehension: How metacognitive strategies and motivation moderate the text-belief consistency effect. Metacognition and Learning, 9(1), 51-74. https://doi.org/10.1007/s11409-013-9111-x

Phakiti, A. (2003). A closer look at the relationship of cognitive and metacognitive strategy use to EFL reading achievement test performance. Language Testing, 20(1), 26-56. https://doi.org/10.1191/0265532203lt243oa

Plonsky, L. (2011). The effectiveness of second language strategy instruction: A metaanalysis. Language Learning, 61(4), 993-1038. https://doi.org/10.1111/j.14679922.2011.00663.x

Plonsky, L., \& Oswald, F. L. (2014). How big is "big"? Interpreting effect sizes in L2 research. Language Learning, 64(4), 878-912. https://doi.org/10.1111/lang.12079

Pressley, M. (2006). Reading instruction that works: The case for balanced teaching (3rd ed.). New York: The Guilford Press.

Salatacl, R., \& Akyel, A. (2002). Possible effects of strategy instruction on L1 and L2 reading. Reading in a Foreign Language, 14(1), 1-17.

Schwartz, A. I., Mendoza, L., \& Meyer, B. (2017). The impact of text structure reading strategy instruction in a second language: Benefits across languages. The Language Learning Journal, 45(3), 263-281. https://doi.org/10.1080/09571736.2013.837092

Smith, F. (1985). Reading (2nd ed.). Cambridge, UK: Cambridge University Press.

Spörer, N., Brunstein, J., \& Kieschke, U. (2009). Improving students' reading comprehension skills: Effects of strategy instruction and reciprocal teaching. Learning and Instruction, 19, 272-286. https://doi.org/10.1016/j.learninstruc.2008.05.003

Tierney, J. E. (Ed.) (2005). Reading strategies and practices (6th ed.). Boston, MA: Pearson Education, Inc.

Urquhart, A. H., \& Weir, C. J. (2014). Reading in a second language: Process, product and practice (2nd ed.). New York, NY: Routledge. https://doi.org/10.4324/9781315841373

Urquhart, S., \& Weir, C. (1998). Reading in a second language: Process, product and practice. New York, NY: Longman.

Ying-Chun, S., Chern, C. L., \& Reynolds, B. L. (2018). Bringing extensive reading and reading strategies into the Taiwanese junior college classroom. Reading in a Foreign Language, 30(1), 130-151.

Zhang, L. (2008). Constructivist pedagogy in strategic reading instruction: Exploring pathways to learner development in the English as a second language (ESL) classroom. Instructional Science, 36(2), 89-116. https://doi.org/10.1007/s11251007-9025-6

Zhang, L., Goh, C., \& Kunnan, A. (2014). Analysis of test takers' metacognitive and cognitive strategy use and EFL reading test performance: A multi-sample SEM approach. Language Assessment Quarterly, 11(1), 76-102. https://doi.org/10.1080/15434303.2013.853770 
JIA-YING LEE received her PhD in Foreign Language and ESL Education from the University of Iowa, USA. She is currently an assistant professor in the English department at Tamkang University, Taiwan. She has wide-ranging interests in TESOL and applied linguistics. She has had articles published in refereed journals including ELT Journal, Language Teaching Research, Reading in a Foreign Language, and Taiwan Journal of TESOL.

\section{Appendix 1}

\section{Test-taking strategies}

(Reprint of Lee's [2018] test-taking strategies with permission)

\section{Strategy Category 1: word-based/lexico-grammatical strategies.}

1. Using the understanding of vocabulary to select the correct answer.

2. Considering the word form by the knowledge of English grammatical rules.

3. Considering the word tense voice by the knowledge of English grammatical rules.

4. Considering the fixed expressions or idioms in English.

5. Considering the verb tense by focusing on a time phrase.

6. Figuring out the target vocabulary by focusing on its roots.

\section{Strategy Category 2: sentence-based strategies.}

7. Using the understanding of the overall context to infer the option.

8. Taking advantage of semantic clues.

9. Paraphrasing or translating sentences to enhance understanding.

10. Jump immediately to the part which contained the missing word and focus on its neighboring part.

11. Reread the sentences that are not clear or understandable.

Strategy Category 3: reading comprehension strategies.

12. Reading all the questions first as a mental note before going on to the passage.

13. Skimming the passage quickly to note the chief points before reading the questions.

14. Reading the question before looking for clues in the related text.

15. Rereading a portion of the passage carefully if it seemed to contain a possible answer.

16. Extracting the key sentences that convey the main information.

17. Matching the key word in the question/options to the text.

18. Focusing on titles, names, numbers, quotations or examples.

19. Identifying the relationship between the two passages.

\section{Strategy Category 4: technical approaches.}

20. Using the process of elimination to achieve an answer.

21. When struggling with answer options, focusing on the part that may contain potential answers.

22. Skip the questions that are perceived to be difficult and time-consuming.

23. Using background knowledge in educated guesses.

24. Calculating the remaining time in order to adjust the reading speed. 


\section{Appendix 2}

Test-Taking Strategy Survey

(Note. The survey was designed on the basis of strategies adopted from Lee (2018))

Instruction: Assign to each item a number between one and five, with smaller numbers indicating that you use that particular item less frequently and the larger numbers indicating their more frequent use.

\begin{tabular}{|c|c|c|c|c|c|}
\hline Strategies & \multicolumn{5}{|c|}{ Frequency } \\
\hline \multicolumn{6}{|l|}{ I. Word-based/lexico-grammatical strategies. } \\
\hline 1. Using the understanding of vocabulary to select the correct answer. & 1 & 2 & 3 & 4 & 5 \\
\hline 2. Considering the word form by the knowledge of English grammatical rules. & 1 & 2 & 3 & 4 & 5 \\
\hline 3. Considering the word tense voice by the knowledge of English grammatical rules. & 1 & 2 & 3 & 4 & 5 \\
\hline 4. Considering the fixed expressions or idioms in English. & 1 & 2 & 3 & 4 & 5 \\
\hline 5. Considering the verb tense by focusing on a time phrase. & 1 & 2 & 3 & 4 & 5 \\
\hline 6. Figuring out the target vocabulary by focusing on its roots. & 1 & 2 & 3 & 4 & 5 \\
\hline \multicolumn{6}{|l|}{ II. Sentence-based strategies. } \\
\hline 7. Using the understanding of the overall context to infer the option. & 1 & 2 & 3 & 4 & 5 \\
\hline 8. Taking advantage of semantic clues. & 1 & 2 & 3 & 4 & 5 \\
\hline 9. Paraphrasing or translating sentences to enhance understanding. & 1 & 2 & 3 & 4 & 5 \\
\hline $\begin{array}{l}\text { 10. Jump immediately to the part which contained the missing word and focus on its } \\
\text { neighboring part. }\end{array}$ & 1 & 2 & 3 & 4 & 5 \\
\hline 11. Reread the sentences that are not clear or understandable. & 1 & 2 & 3 & 4 & 5 \\
\hline \multicolumn{6}{|l|}{ III. Reading comprehension strategies. } \\
\hline 12. Reading all the questions first as a mental note before going on to the passage. & 1 & 2 & 3 & 4 & 5 \\
\hline $\begin{array}{l}\text { 13. Skimming the passage quickly to note the chief points before reading the } \\
\text { questions. }\end{array}$ & 1 & 2 & 3 & 4 & 5 \\
\hline 14. Reading the question before looking for clues in the related text. & 1 & 2 & 3 & 4 & 5 \\
\hline $\begin{array}{l}\text { 15. Rereading a portion of the passage carefully if it seemed to contain a possible } \\
\text { answer. }\end{array}$ & 1 & 2 & 3 & 4 & 5 \\
\hline 16. Extracting the key sentences that convey the main information. & 1 & 2 & 3 & 4 & 5 \\
\hline 17. Matching the key word in the question/options to the text. & 1 & 2 & 3 & 4 & 5 \\
\hline 18. Focusing on titles, names, numbers, quotations or examples. & 1 & 2 & 3 & 4 & 5 \\
\hline 19. Identifying the relationship between the two passages. & 1 & 2 & 3 & 4 & 5 \\
\hline \multicolumn{6}{|l|}{ IV. Technical approaches. } \\
\hline 20. Using the process of elimination to achieve an answer. & 1 & 2 & 3 & 4 & 5 \\
\hline $\begin{array}{l}\text { 21. When struggling with answer options, focusing on the part that may contain } \\
\text { potential answers. }\end{array}$ & 1 & 2 & 3 & 4 & 5 \\
\hline 22. Skip the questions that are perceived to be difficult and time-consuming. & 1 & 2 & 3 & 4 & 5 \\
\hline 23. Using background knowledge in educated guesses. & 1 & 2 & 3 & 4 & 5 \\
\hline 24. Calculating the remaining time in order to adjust the reading speed. & 1 & 2 & 3 & 4 & 5 \\
\hline
\end{tabular}

